\title{
TORRES VILLARROEL, POETA GONGORINO
}

\section{Planlcamiento}

Nos proponemos llamar la atención de los estudiosos sobre un pocma de 'Torres Villarrocl prácticamente desconocido: la Conquisha del rino de Nápoles. Se trata de una obra épica relativamente extensa (23 I octavas) (uue, a nuestro juicio, merece ser rescatada del olvido. Lo merece por tres razones: por sus valores intrinsecos (alpreciables, aunutue no de priner orden), por ser ma muestra única del talento de su autor para el género épico y por constituir un ejemplo destacado de la supervivencia del gongorismo en la primera mitad del siglo xin '. Siendo, en cuanto a su motivación, una obra de circunstancias, no está, sin embargo, escrita con desgana, al menos no lo está en su mayor parte. Parece como si, al componerla, Torres Villarrocl se hubiera ido encariñando con su, para él, inusitado tena épico, acaso por sentirse satisfecho del resultado ohtenido. lista satisfaccion se justificaría si se piensat en el resto de su obra poética, abundante en desmaños y caídas en lo prosaico. Por otro lado, al ser la Conquisla una obra ceñida a hechos históricos, le cupo en ella soslayar el recurso a la pura invención, en la que habría naufragado fácilmente. A ello hay que añadir que, si bien el retorcimiento gongorino $y$ la clevación de tono que el autor se impone son a menudo causa de imprecisiones de sentido y de pasajes clesangelados, logra salvar cualidades positivas que, en los mejores momentos, se condensan en estrofas o versos apreciables. Iin todo caso, la dignidad media del pocma queda asegurada. Torres Villarroel respeta arui, además, escrupulosamente el carácter cncumbrado del tema, sin punta de ironía o coinicidad, y sin incurrir en ninguno de los desplantes o desacatos que sucle diseminar con prodigalidad, incluso en sus escritos

$2 V$. sobre ésta el trabajo de Nigit, Gibinimsing, Ia fortuna de Gingora

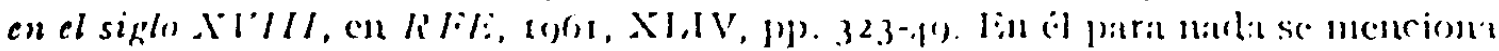
la Conquista, pero el antor scñala (nota 3 a la p. $33^{x}$ ) alguna influencia aislada de Góngora sobre l'orres. 
graves. A lo dicho se suma el carácter culto y elaborado de la Conquista. La abundancia de alusiones (históricas, mitológicas) es prueba adicional de una actitud morosa, erudita, excepcional en un autor que habia redactado precipitadamente buena parte de sus libros.

\section{Propósito}

El poema épico de Torres Villarroel objeto de nuestra atención lo designamos abreviadamente como Conquista en el cuerpo de este trabajo. Su título y subtítulo completos, en la edición madrileña ${ }^{1}$ de I735 (pequeño volumen de 48 páginas en cuarto) reza así: "Conquista del reino de Naipoles por su rey don Carlos de Borbón. Escrila en octavas por cl doct[or] d[on] Dicgo de Torres y Villarroel, del gremio y claustro de la universidal de Salamanca y caledrático de prima de matemáticas en propiedad. Dedicada a la reina Nuestra Señora, doña Isabel Farnesiou. Iin la edición de $175^{2}$, de Salamanca, primera de las obras completas de 'Torres y hecha aún en vida de éste, y en la que la Conquista figura al final del volumen VII ( $p$ p. 229-86), el título se ha abreviado así: "Conquisla del reino de Nápoles por su rey don Carlos de Borbón, en octavas. Dedicada a la reina Nuestra Señora, doña Isabel Farnesion. Esta edición mantiene la dedicatoria a la reina y el prólogo, pero prescinde ya de la censura y de la aprobación, existentes en la de I735. Tanto una como otra llevan al margen -impresas también, aunque con tipo distinto- notas o aclaraciones que unas veces explican alusiones mitológicas, históricas o personales de las estrofas, y otras resaltan el principio de los momentos principales en que se divide estructuralmente el poema.

Pensamos que una edición completa del texto de la Conquista no carecería de interés. Pero, dado que ello rebasa la extensión y las posibiliclades de un artículo, se aplaza para mejor ocasión. Reducido así el propósito de estas páginas, nos limitaremos a adelantar el estudio y la caracterización general del poema y a escoger unas cuantas estrofas que sirvan como breve muestrario de éste, procurando, al mismo tiempo, que resulten aclaratorias de los puntos de vista expuestos.

\section{Fecha}

I a edición madrileña de la Conquista del reino de Nápoles (que hemos utilizado para este trabajo) no lleva mención de fecha. Cabe asignarle,

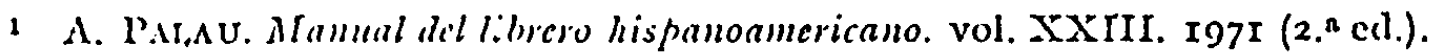
1). 459 b cita ot ra cl. madrileña, Imprenla de M tísica (I 735), cuya existencia no puedo comprobar. 
sin embargo, la de 1735 en atención a las razones siguicntes: 1. a) la $c c n$ sura, debida al padre I'ray Francisco de Béjar, está fechada el I4 de octubre de I735, y la aprobación, del reverenclo Cayetano de Hontiveros, el 20 de scptiembre del mismo año; $2 .^{\text {a) }}$ la Real Orden concediendo a 'l'orres Villarroel el perdón de su clestierro en P'ortugal, y a la que se alude en el prólogo del poema y en el cuerpo de éste, ticne fecha de 3 de noviembre de $173+^{1} ; 3 .^{a}$ ) la calda de la furtaleza de Bitonto en poder de los españoles, suceso ensalzado en la obra, ocurrió el 25 de mayo de ese mismo año $7734^{2}$. Como la redacción de la Conquista corresponde a un acto de gratitud motivado por el perclón real ${ }^{3}$, la fecha citacla para la Real Orden (3 de noviembre de I734) podenos considerarla como punto de arrancue de la idea de escribirla. Las fechas de censura y aprobación (la primera de las cuales, la de aprobación, es de 20 de septicmbre de I735) exigen ya, lógicamente, una lectura previa del poema. Este hubo, pues, de ser redactado entre los dos últimos meses de 1734 y los primeros de 1735 . Como se trata de un escrito de carácter culto, lo que no parece compatible con la redacción precipitada, y como es razonable conceler al autor cierto margen de ticmpo para madurar la idea de escribirlo, resulta preferible eliminar los dos últimos meses de r734 y quedarse más bien con los primeros de I735, época en la que '́orres Villarrocl, reincorporado a su cátedra de Salananca, disfrutaria, además, de tranquilidad y reposo para el trabajo. La publicación liubo de tener lugar a finales de $173.5^{4} \mathrm{o}$, como más tarde, a principios de $173^{6}$. In cualquier caso, el hecho de que la obra ghorifique un suceso reciente de resonancia nacional y el apoyo por parte de la realeza con que se vio favorecida ${ }^{5}$ aseguran una publicación rápida.

1 V. Antonio García Boiza, Don Diego de Torres lillarroel. Ensajo biográfico, Matricl, Iiditora Nacional, 1949, pp. $85-86$.

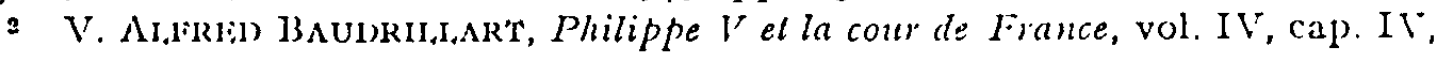
Paris, Tirmin-Diclot, s. a., p. 238.

3 Al perdón real alude Torres en el prólogo al léctor diciendo: mlespués que, por la piedad del rey, Mi señor, estuve entre mis anigos, junté sus voces y tal cual relación de esta conquisitan. La alusión se repite al principio del poena (cn la estrofa séptima, versos 55 y 56 ): "y rompa el curso de mi ahogada vena / cleiclad que romper quiso mi cadcua".

- Al principio de su censura (lel iq de octubre de i 735) Iray lirancisco de Bójar dice: "le orlen y remisión de V[uestra] Aflteza] he visto y leirlo un papel intitulatr) Conquista de Napoles por su rey don Carlos, que intenta dar a luz (cste schundo subrayarkes es mio) el doctor don Diego de Torres.. Ia publicacion scria, pues, positerior a octubre cle 17.35 .

- Iin la portadia de la celicion que sirve de base a cete trabajo se lee: "imureso en Madrid, y por su original (con licencia) en Sevilla, en la Inprenta Real, por la 


\section{El hecho histórico}

La campaña de Nápoles, poetizada por Torres Villarroel en su poema, se inscribe entre los hechos de armas a que da lugar la política de Isabel de Farnesio, que se encamina a conseguir un trono para sus hijos ${ }^{1}$. Lin I720 Lispaña había entrado en la Cuádruple Alianza, pactando con Austria, Francia e Inglaterra la renuncia definitiva al reino de Sicilia - que había pasado al imperio austríaco tras la Guerra de Sucesión originada a la muerte de Carlos II de España- y el reconocimiento de Parma, Plasencia y Toscana como feudos imperiales. A cambio de esto, el emperador austríaco se avenía a que, en caso de no liaber sucesion masculinn, estos territorios pasasen a pertenecer al hijo mayor de los reyes de España. Así, en I73I, el infante Carlos (futuro rey Carlos III) pasa a Parma, con motivo de la muerte sin sucesión masculina del duque Antonio Farnesio. Marcha después a Filorencia, donde el gran duque Gastón de Médicis carecía también de un hijo varón, y allí reside durante varios meses en el palacio Pitti. Ėn uno $y$ otro sitio su presencia es bien acogida por el pucblo. Iistando asi las cosas, Ispaña y lirancia firman, en I733, el primer Pacto de Familia, por el que Luis XV se compromete a defender la causa y los derechos del infante Carlos. Comienza entonces la Guerra de Sucesión polaca y España pone sus miras en Nápoles. I a situación se endurece y el conde de Clavijo se une en Antibes al conde de Montemar, pasando ambos a Italia con tropas españolas. Iistas se concentran en Siena y el infante Carlos (al que su paclre habia nombrado generalísimo) toma el mando de ellas. Iniciada la campaña, Carlos consigue del Papa el libre paso de su gente a través de los estados pontificios. Desde Civita Castellana los españoles avanzan sin encontrar resistencia hasta Mignano, Vairana, Matalone y Aversa. Visconti (virrey de Nápoles) se refugia en la provincia de Bari, adonde el marqués de Mina y el duque de Castropiñano marchan contra él. Nientras esto ocurre, el conde de Charni ataca Nápoles. I,os castillos de San Telmo y Novo se rinden a los españoles. El ro de marzo de $173+$ don Carlos entra triunfalmente en Nápoles, del que días antes, en Aranjuez, Felipe $V$ (su padre) lo ha declarado rey. Visconti, que se habia hecho fuerte en Bitonto, cerca de Bari, es ahora

reina, Niucstra señora, castellana y latina, de don Diego López de Haro, en calle de Géllovan.

1 Jelipe V' se casó con Isialel de l'arnesio después de haberse quedado viudo Y con dos hijos varones, I nis y lemando, al primero de los cuales correspondia, lógicamente, el trono de Isspaña. 
vencido por el concle de Montemar, que se apunta una victoria resonante ${ }^{1}$. Esta victoria va a valerle el título de duque y el gobieno vitalicio de Castel Novo ${ }^{2}$.

\section{Conlcnido del pocma}

Il autor comienza por lamentar su presente estado de infortunio en contraposición a una pasada época de felicidad ${ }^{3}$ (estrofas I a 3 ). Vienen, luego, una estrofa de enlace (la 4) y la dedicatoria-invocación dirigida a la reina doña Isabel de I'arnesio, en la que pide a ésta que lo inspire (estrofas 5 a I I). Se anuncia cuál va a ser el contenido del pocma: la grandeza del futuro rey Carlos III", patente en su estirpe y en sus liechos gloriosos (estrolas I2 a IS). Se presenta al infante despidiéndose de sus padres (estrola I9) y se describe, a continuación, su travesía triunfal hasta Italia, al modo de la de un dios mitológico (estrofas 20 a 24). Lil desembarco en Parna y la presentación de don José I'atiño ${ }^{5}$, primer ministro, y del conde de Castropiñano ${ }^{6}$, teniente general, ocupan las estrofas 25 a 33. Después, Carlos sale de Parma y entra en Florencia, donde es admirado y aclamado (34 a $3 S$ ). Se congrega el ejército español, que cobra indomable ánimo a la sola vista de su caudillo (39 a 4I). Continúa la glorificación del infante: tierras y gentes se entregan espontáneamente, en cuerpo y alma, a Carlos, que recoge en todas partes aclamaciones y confirma, magnánimo, mercedes y privilegios (42 a 54 ). 'Tras la rendición de varios castillos, a lo que se alude sólo de pasada (55 a 57), Carlos cutra triunfante en Nápoles y se vuclve a describir su apostura y magnificencia, así como las de su caballo, del acompanamiento real y de la ciudad engalanada (58 a 72 ). Se expone, de nuevo, la magnanimidad de Carlos y se encarece el feliz destino de Nápoles por pasar a pertenecer a la corona de tal monarca (73 a 85 ).

1 La fecha de la batalla de Bitonto fue, como queda dicho, el 25 de mayo de 1734 .

2 La politica extcrior española motivada por las ambiciones de Isabel de larnesio la expone detalladamente BAUDRII.ART, op. cit. V. también P. VOITFS, Carlos III y su tiempo, Barcelona, Juventud, I964, y li. de 'Tapia Ozcariz, Carlos III y su época. Madricl, Aguilar, I962, especialmente pp. 73-168.

3 Considerado biográficamente, lo lógico scria más bien lo contrario, ya que, al escribir esto, Torres disfrutaba de una buena época, tras el perdón real. Pero el tecuerdo de su desgracia anin cercana lubo de tener mist fucrza.

- Iil entonces infante Catrlos no se corona rey de Iispaña hasta el año I 759.

- liue printer ministro de lielipe $V$ y orginizó el ejército y la armadia.

- Mandó las tropas españolas, juntancnte con el marqués de la Mina, contra el virrey Visconti. 
I legado a este punto, el poema cambia de enfoque. Mientras Carlos queda como triunfador en Nápoles, el conde de Montemar se apodera de Bari (86 a 94). Se canta, luego, el asedio de Bitonto, con los pormenores estratégicos correspondientes ( 96 a I06), y se enumera, enaltecienclo a la ver. su cuna y hechos gloriosos, a los nobles que figuran en el bando español ${ }^{1}$ (I07 a I3I). Amanece el 24 de mayo de 1734 y se entabla firmemente la batalla ( $\mathrm{r}_{32}$ a $\times 40$ ), que, en la tarde de ese nismo día, es interrumpida astutamente por el conde de Montemar, que figura al mando del ejército (I4I y I42). Amanece el día $25 \mathrm{y}$, a pesar de la superioridad del enemigo, el ánimo exaltado de los españoles consigue una rápida y total victoria ( $\mathrm{r}_{43}$ a $\mathrm{r} 83$ ), que se consuma en el alborear apoteósico del día 26, sienclo los vencidos objeto de trato caballeroso y magnánimo por parte de Montemar ( 184 a I96). Se dedican dos estrofas (I97 y rgS) a glorificar a los cafdos españoles ilustres (que sólo son tres) $y$, acto seguido, se canta la marcha del ejército a Bari, plaza que también es vencida, asl como los nuevos actos de magnanimidad de los dominadores (I99 a 205). Tras su resonante triunfo, el conde de Montemar regresa a Nápoles para informar al rey, que lo honra abrazándolo 2 y colnúndolo de parabienes (206 a 209). Iil conde de Charni se queda en Nápoles en el cargo de virrey y se cita a otras personas a las. que Carlos confió puestos relevantes (2ro a 2r3). Por último, se enumeran otras acciones bélicas que completan y consolidan la victoria española (2I + a 229) y termina el poema con la consabicla invocación (229 a 23x).

\section{Prólogo doclrinal}

Eil prólogo al lector que pone Torres Villarroel al frente de su poema constituye, a pesar de ser muy breve, una vía de acceso para conocer las ideas de su autor accrca de qué cosa sea la poesía épica. De ahí que quepa calificarlo, en sentido amplio, de doctrinal. Hay que decir, ante todo, que, a diferencia de otros escritores del siglo xvirI ${ }^{3}$, Torres sabla

1 Issta enumeración, extensa y con motivos reiterados, constituye una prueba mis del carácter oportunista, de obra de circumstancias, que tiene el poema. Torres se propone no omitir la mención de ninguno de los personajes importantes o influyentes participes en la empresia.

2 l'recisamente por su victoria de nitonto el conde de Montemar iba a obtener cl titulo de duque. $A$ ello parece aludirse cu la estrofa 208 (versos 166r y 1602): "fan cultañables fucron los alrazos (= alude a los que dio cl rey al conde) /que in:plision di carcicler los solpichom.

3 Iin culnto a teoria litcratria -y tambien con referencia al género épienel siglo xin se carncteriza por un dogmatismo más inflexible que el que inspiró 
advertir el desacuerdo entre las ideas rígidas de los teorizadores (propensos por naturaleza al perfeccionismo abstractizante) y la aplicación concreta de éstas a sus propias obras: "dan los cánones ficles para la expresión de los pocmas y cllos mismos las quebrantaron muchas veces en los suyos" dice, refiriéndose a '́asso y Castelvetro. Sin embargo, y aun a conciencia de esto, acata las normas, por así decirlo, "vigentes" del género y reconoce que la modernidad de los hechos que se dispone a cantar representa una irregularidad de primer orden, dado que "lo nuevo de la historia estrecha la invención y los episodios, que son toda la hermosura y ser de los poemas" ${ }^{1}$. Pero, a continuación, se acoge al precedente ilustre del Príncipe de Lissquilache, que, en su Nápoles recuperalla ${ }^{2}$, cantó también una acción cronológicamente cercana, aunque no tanto, al momento en que escribia. No encontramos, pues, lasta ahora nada especialmente innovador; lo dicho se atiene a una tradición antigua no trastornada cn su esencia ${ }^{3}$. En realidad, lo que se hace en este prólogo es mezclar hábilmente la exposición de puntos de vista doctrinales con la justificación de las limitaciones o deficiencias de la obra, limitaciones o deficiencias éstas que vendrían dadas por el escaso tiempo disponible, por el ningún ejercicio en el géncro épico, por la intranquilidad del ánimo y por la merma de facultades atribuible a la edad 4. Torres sale también al paso de posibles impugnaciones de inexactitud histórica alegando que, cuando tenían lugar los hechos que en-

las producciones alel Siglo de Oro. V. sol,re ello liRANk l'nikCE, La pocsia épica del Siglo de Oro, Madrid, Gredos, 1961, pp. 40-102.

1 I a tendencia a formar grupo aparte con los poenas de contenido exclusiva o principalmente histórico se expresa también, desde antiguo, en los teorizadores del género.

2 Su título completo es Nápoles recuperada por el rey don Alonso (se refiere a Alfonso $\mathrm{V}$ de Aragón), que dedica a la majestad del rey Nuestro Señor, don Felipe IV el Grandc, Francisco de Borja, Principe de Esquilache. Consta de doce cantos en octavas. La edición príncipe, Zaragoza, $16_{5} \mathrm{I}$, lo califica de "poema heroicon. I,os temas napolitanos los cantó también lirancisco Dr TRILIOO Y IIIGUIROA en su Napolisea, poema heroico y panegirico, en ocho cantos, también en octavas, que se publicó en Granada el mismo año 1651 .

3 Hay que tener en cuenta que la Poética de I,uzán, primer intento importante de clirigir la creación literaria hacia horizontes nuevos, no aparece hasta dos años después: ell 1737 .

- Iin los numerosos prólogos que lorres antepone a sus obras sucle siempre justificarse de un modo $u$ otro. No pierde de vista su conveniencia profesional de hombre de letras. Iin él hay mucho de "buen sentido" burgués. V., cn relacion con csto, el trabajo de JunN Maricuni, Torres l'illarnel: aulobiografia burguesa al hispánico modo, en P'upeles de Son Armadans, matzo I965, XXXVI, núm. CVIII. pp. 297-306. 
salza, él carecía, por hallarse en el destierro, de todo medio adecuado de información, teniendo luego que recurrir a lo que le contaron sus amigos y a "tal cual relación de esta conquista". Por todas estas razones -proximidad cronológica de los hechos, falta de invención personal y de agregaciones imaginativas, deficiencias de las fuentes de información, dificultades personales-a las que segurannente habria que unir aún la brevedad ", aunque no se aluda a ella, Torres Villarroel se considera ya suficientemente justificado en cuanto a la naturaleza de su obra y en cuanto a las posibles deficiencias de la misma y se declara dispuesto a empezarla "liuyendo de todo lo que pueda parecer poema" 2 .

En la segunda mitad del prólogo, Torres caracteriza su estilo diciendo que "sicmpre fue humilde y aun abatido" y que, aunque pudiera con su esfuerzo darle alguna altura, no es de la opinión de "que sean útiles para la elevación de lo heroico las voces ásperas y ruidosas porque ellas son espanto de necios y burla de entendidos". $Y$ agrega que "con ellas se avinagra la dulzura y el numen y, mezcladas con la oscuridad, hacen intolerable la locución y desconocida la sentencian " ${ }^{3}$. Todo esto parece corresponder a un ideal de sencillez y claridad. Pero no hay que olvidar, sin embargo, la considerable dimensión de falsa modestia que encierran tales afirmaciones. Ello unido a que, aun cuando admitiésemos la sinceridad de tales juicios, la lectura de la Conquista se encargaría de desmentirlos en gran parte, haciéndonos ver cuánto tributo pagó su autor a la vilipendiada oscuridad.

\section{Torres y el Principe de Esquilache}

En el prólogo a la Conquista, Torres Villarroel hace referencia, como acabamos de ver, al poema Nápoles recuperada, toma ideas del prólogo a esta obra e incluso reproduce casi literalmente alguna frase del mismo. Cabría, pues, pensar en una influencia general de un poema sobre el otro, que vendría reforzada por la afinidad temática. Pero esta influencia, si se da, es mínima. Ein Iisquilache la acción gloriosa, cuyo

1 La Conquista se compoue de 23 I estrofas, frente a las r.I79 de que consta el poema del Principe de lisquilache.

2 Por poema henos de entender açul nobra épica versificada, de extensión considerable, dividida en cantos y con abundancia de elenentos inaginarios o irreales.

3 Torres hablia aquí por boca de lisquir,ncini, que en el prólogo a su Napoles reupirala dice: the procurado huir de palabras ásperas y de ruido... que son espinto de los ignorantes y risa de los cuerdos, pues con cllas se falta a la dulzura y al muncro $y$, mezclarlas después con oscuridad, hacen intolerable la locución $y$ aborrecible la sentencian. V. en $B A E$, vol. XXIX, pp. 289-9o. 
carácter histórico scrialaba él mismo en el prólogo, está casi alıgada por una profusa hojarasca (en la que se advierten, sobre todo, elementos caballerescos y pastoriles), micntras que 'lorres Villarroel se ciñe a los hechos, sin deformaciones imaginativas muy scusibles. Las resonancias gongorinas, por otra parte, frecuentes en 'lorres y caracterizadoras de los mejores pasajes de su poema, sólo esporádicamente se dan en Nápoles recuperada ${ }^{1}$, obra en la que es muy apreciable la influencia garcilasiana. Ialtan también en '́orres las descripciones de enseres y pertrechos, así como las arengas, parlamentos e invocaciones ${ }^{2}$. I a enumeración de personajes participantes sí se esbo\%a en el Príncipe de Escquilache, pero sin alcanzar la pretensión de exhaustividad que tiene en 'lorres. $\Lambda$ esto hay que agregar que la Conquisla, aun con los defectos aludidos, consiguc, con mucho, superar el extenso pocma, aproximadamente un siglo anterior ${ }^{3}$, a cuya autoridad se acoge. Libre, pues, de las agregaciones imaginativas de Esquilache, que no cuadraban con su personalidad de escritor, 'Torres toma, casi al pie de la letra, el hecho histórico (campaña napolitana del infante Carlos) con sus precedentes inmediatos, lo versifica cuidadosamente (como compete a la dignidad del tema y a su propósito de pancgirista) y, con Góngora como mentor y guía de los pasajes más inspirados, consigue una obra de aciertos apreciables, superior, en todo caso, al farragoso poema cuyas ideas doctrinales (expuestas en el prólogo del mismo) sí utiliza y sigue, haciendo de ello alusión y reconocimiento expreso.

\section{La "Conquista", obra gongorina}

Casi todos los que se han ocupado de la obra de 'Torres Villarroel coinciden en señalar su carácter de escritor vertido miméticamente hacia los clásicos del siglo xvin y, en primer lugar, hacia Quevedo. Ein el caso concreto de la Conquisla del reino de Nápoles esta característica, que, por supuesto, ha de ser analizada y precisada 4 , recibe

- Por ejemplo en la décina estrofa del canto primero: "cuando resuelto ch su dorada popa / Alfonso dio sus leños al amigo / del argonaula, robador de Europa / y de su justo llanlo fiel testigon.

2 Ia extensión de la Conquisla, mucho menor, dificulta, naturalmente, el recurrir a tales ingredientes. P'ero sí cabria un esbozo de éstos y ni aun eso se encuentra.

3 Aunque el pocma de lisquilache aparece en I65I, el autor declara en el prólogo que tha nuclios años que está cscrito".

- Fin otra ocasión intentaremos aportar algunas precisiones sobre èste particular. 
confirmación, pero ahora es más bien Góngora quien influye sobre Torres y lo condiciona. İl gongorismo de la Conquista es apreciable en una serie de rasgos. Ante todo, en el léxico. El cotejo de éste con las listas de palabras incluidas por Dámaso Alonso en La lengua poélica le Gúngora -estas listas incluyen los cultismos de la Soledad primera, los anteriores a ésta y una relación de términos censurados por los anticulteranos de la época (220 de los cuales fueron usados por Góngora) y cuyo total se eleva a 842 , arroja 257 coincidencias, lo que constituye una proporción apreciable, dadas las dimensiones reducidas de la obra de 'Torres ${ }^{1}$. Pero, de todos modos, y considerando que éste escribe en in momento en el que las innovaciones culterano-gongorinas habían experimentado ya un largo proceso de adaptación y aclimatamiento, parece excesivo aducir las coincidencias léxicas como prueba principal del gongorismo. Gongorinos son también en la Conquista otros rasgos que se reiteran hasta el punto de constituir constantes caracterizadoras. Así, la colocación de la palabra más bella, inusitada o sugerente en la cumbre rítmica del verso, las antítesis, el hiperbolismo, las referencias a la mitología y la historia grecolatinas, los versos simétricos ${ }^{2}$, la reiteración de fórmulas sintácticas ${ }^{3}$, la intensidad con que se expresan las

1 Iin esta lista de coinciclencias destacan voces tan significativas como canoro, cerilco, émulo, febeo, flamante, hemisferio, hibleo, hidropico, hircano, inexpugnable, intrepido, obelisco, palestra, pensil, polo, progenie, próvido, remora, restituir, tremolar, Hofio, que figuran todiss en la lista de cultismos de la Soledad Primera: cf. D. Aronso, La lengua podtica de Góngora, Madrid, 1935, pp. 48-66. Palabras como inclito y orbe, por ejemplo, figuran en la lista de cultismos gongorinos anteriores a la Soledad Primera y no existentes en ésta, cf. op. cit., pp. 77-79. Otras como aura, cláusula, concento, parasismo, pielago, plaustro, plectro, nutilante, solio, tirio, trémulo y viclima coinciden con la lista de las palabras parodiadas o censuradas en el s. xvir, cf. op. cit., pp. 95-108, y, de ellas, todas salvo dos (planstro Y solio) las usó Góngora.

2 Citamos ejemplos: "ronca la voz y roto el instrumento" (estrofa $\mathrm{r}$, verso 8), * fuerte Minerna y discursiva Palas" (estrofa 39, verso 8), "Marte sin armas y sin truenos Jove" (estrofa 48 , verso 8), "que nieva chispas, centellea espumas" (estrofa 70, verso 8), "dulce cante y armónico agonice" (estrofa 74, verso 8), "la arena escarpas y la guija fososn (estrofa 96, verso 8), "pisa los riesgos, los rigores huellan (estrofa ror, verso 2). "da al mar asombro y a la tierra espanton (estrofa 104, verso 8), "'minindos arrolla, mares atropella" (estrofa 104, verso 4). "montes de estorbos, riscos de cmburazos» (estrofa 102, verso 8), "baticnlo cercas, allanando alluras* (estrofa ro3. verso 1), "ti crcesos siffie ni uculajas mira" (estrofa 135 , verso 8), "la muerte leve y al horror suare (estrola 152, verso 8), ufloridas mieves y mevadas flores" (est rofa 153, verso 8). Nótese que prícticamente la totaliclad de estos versos simétricos se encuentra al final le las estrofas, lo que indica que se los sentía como especialmente bellos.

3 Asi, por ejemplo, el uso de ser con valor de 'servir de' seguido de la prepo- 
scusaciones visuales y sonoras. Aun cuando todo csto no sea exclusivo de Góngora, sino que éste represente la culninación de toda una corriente anterior, según hizo ver Dámaso Alonso 1, la manera especial de manipularlo 'forres revela el influjo directo del gran cordobés. lil gongorismo es, sobre todo, apreciable en la primera mitad del poema, cuando se describe la travesía del infaute Carlos hassta Italia y su recorrido triunlal por aquel país, parte ésta cn la que la tenuiclad del acontecimiento narrado permite entregarse casi sin trabas a la pura elaboración estética. En todo caso -y como era de esperar y de temer- Torres se mantiene muy por debajo de la altura media de su modelo. Ni llega a alcanzar su dificultad conceptual, ni su complicación sintáctica ni su tersura formal. 'Tampoco debió, por otra parte, de proponéssclo ${ }^{2}$. Los pasajes que necesitan "tradıcción" son pocos $y$, cuando hay alguno, la dificultad se debe en buena parte a inpericia del autor, que fuerza unas veces y difunina otras el sentido de las palabras, o liace erosioncs al rigor de la construcción sintáctica ${ }^{3}$. Pero, en cualquier caso, y aun con las salvedades que anotamos, forres acierta a menudo y consigue en su poema una calidad media más que suficiente para que se lo incluya, con toda justicia, entre los gongoristas destacados de la primera mitad del siglo xvirr.

\section{La "Conquista", obra de arte. Su estructura}

Iin contra de lo que cabría esperar, dacla su extensión más bien reducida, la Conquisla da cabida a dos acciones distintas: la presencia triunfal del infante Carlos en Italia y el asalto y conquista de Bitonto. De la primera es héroc, naturalmente, el infante mismo, futuro Carlos III; de la segunda, el conde de Montemar, "Mlarte andaluz". La primera, exenta de la violencia de lo bélico, es mucho más apta para el colorismo y pomposidad, para lo decorativo y suntuario, y a clla corresponden los momentos de mayor inspiración artística. Ia segunda, cent-

sición $a$, calco de las construcciones latinas de ISSSL más dativo. Taunlién el recurso a la fúrmula $A$ si $B$ : "de ambar a IIesperia, si de "roma a Italia" (estrofa 37 , verso 8), "cl yugo dulce, si la carga leve" (cstrofa 85, verso 8), "por sol infanle, si por rey mancebo" (estrofa 207, verso 6).

- In su ya clásico trabajo La lengua poélica de Gúngora.

2 De las opiniones sobre el particular, discminadas en su obra, se desprente que Torres, cn buena parte por didactisuo, cra partidario de la "claridadb. L'ero se sabe muy bien que estas afimacioncs no implican que se deje de rendir, cu mayor o menor medicla, culto a la dificultad gongorina.

3 Confiamos en laicer ver que es asi en los comentarios a las estrofas reproducidas al final del trabajo. 
trada en lo guerrero, se atiene, en cambio, casi al pie de la letra, a la historia, deja menos lugar para el embellecimiento y la transformación estética y adolece de caidas y de desmayos, perceptibles sobre todo en la extensa enumeración de aristócratas participantes en la empresa de Nápoles, pasaje éste en el que cierta reiteración y desgana resultaban difíciles de evitar.

Iin virtud de la duplicidad citada y del carácter más propiamente épico del episodio de Bitonto, existía el riesgo de que la figura del monarca resultase oscurecida por la del conde de Montemar, héroe y caudillo del acontecimiento gucrrero que sirve de motivo principal, por no decir único, de la obra. Pero 'Torres, hábilmente, ha tenido buen cuidado de insistir en la grandeza de Carlos, en su magnanimidad, en su prestancia, en su energía, en el encanto irresistible de su persona, haciéndolo así artífice, al modo de un dios que anonada con su solo esplendor, de una gloriosa victoria moral. Y, cuando describe la calda de Bitonto, sin regatear las alabanzas al conde de Montemar, se cuida muy bien de realzar el indomable ánimo de los españoles, de todos y cada uno de cllos, lo cual hace que la victoria tenga más de apoteosis patriótica ( $y$, por tanto, colectiva) que de ensalzaniento de la persona del caudillo. Una vez más, el catedrático salmantino se mantiene con los pies bien asentados en la tierra.

Esta duplicidad es, por otra parte, consecuencia del carácter de obra de circunstancias que la Conquista tiene en un principio. I,os primeros sucesos cusalzados en clla (desembarco de Carlos en Parma, por ejemplo) tuvieron lugar en $1732 \mathrm{y}$, desde entonces liasta I734, 'lorres permanece insensible. Iis su liberación por obra de la bondad real la que lo muevc, cn ese año, a la enıpresa poética y, necesitando entonces de un pretexto exterior, de un suceso glorificable, la conquista de Bitonto (acción de no mucha importancia en sí misma) va a proporcionárselo, pero sin que se olvide por ello de que es a la realeza a la que deben dirigirse ante todo sus alabanzas ${ }^{1}$.

Considerada desde el punto de vista estrictamente poético, la Conquisla es obra desigual. Acostumbrado a versificar de modo más despreocupado y valiéndose de formas estróficas más fáciles, Torres tropieza aqui a menudo con las dificultades que él mismo se impone, lo que da lugar a imprecisiones, opacidades y prosaísmos. El coeficiente de originalidad personal es cscaso más bicn, tanto en cuanto al tema

1 In su dedicatoria a Isabel de liarnesio Torres deja traslucir claramente sus motivaciones: kaliora que, más favorable la fortuna, me concecle un argumento en cuya gloriosa cxaltación ticue la mayor parte el espiritu de Vuestra Majestad, escribo cstas cliusulas..." 
(hecho histórico) como en cuanto a su tratamiento (gongorino y fiel a las normas tradicionales del género épico). Sin embargo, la recreación torresiana 110 carece de aciertos apreciables, sobre todo si se la considera en relación con la mediocre calidad media de la poesía de la primera mitad del siglo xvm. 'lorres logra alguna de las buenas cualidades de Góngora (sobre todo, la brillantez y la transmutación estética del mundo objetivo), aunque no lo siga en la implacable coherencia de la sintaxis y sólo muy de lejos en la capaciclad de invención metafórica. Por otra parte, la aludida duplicidad temática encuentra también su equivalencia en el plano formal. La presencia triunfante de Carlos en Italia está tratada a modo de apotcosis irreal, como despliegue de formas, impulsos y colores, desmedidos por su belleza, violencia o intensidad. Ista parte del poena es, por tanto, la más gongorina, ya que tiene con Góngora la importante afinidad de servirse del argumento (o tema más bien) como simple punto de arranque para la creación de un mundo poético propio. A diferencia de esto, la descripción del asalto y conquista de bitonto, aunque manticne el tono brillante y elevado, necesita, dada su apoyatura listórica, atender en mayor medida al "asunto" y a ella corresponden principalmente los prosaísmos y las caílas. Lin esta parte el influjo de Góngora se mezcla, además, con el de la tradición propiamente épica, sobre todo a partir de Ercilla, y de ahí una mayor sencillez, una andadura más lineal de la versificación, compatible, sin embargo, con lo encumbrado $y$ solemue del tono.

I0. Métrica

La totalidad de la Conquista está escrita en octavas reales, con arreglo al esquema clásico $\triangle B A B A B C C$. Como es sabido, fue Errcilla quien, en su Araucana, consagró la octava como estrofa característica de la narración épica, papel en el que se consolidó a lo largo del Siglo de Oro y en el que persevera en el xvin ${ }^{1}$. Eligiendo la octava como forma mé trica de su poema, 'Torres se manticne, pues, dentro de la corriente más tradicional y unánimemente aceptada.

La versificación de toda la obra es, en general, correcta. De rez. en cuando aparecen versos forzados, pero en número muy cscaso. Los que están abiertancnte mal medidos suelen ser atribuibles a error de la

1 De la octava real dice Tomís Navarro que fue ula estrofa cudecasilábica de forma orgínica que se mantuvo con más fimeza en su antigun nivels. V. Mttrica española, Siracusa-Nueva York, 1956, p. 29r. Mris tarde el Romanticismo la extenderá a todas las manifestaciones de la poesla grave. 
edición y pueden enmendarse con facilidad. En algún caso la necesidad de encajar un nombre propio inoportuno (igajes de la adulaçiónl) estropea irremediablemente un verso, pero es de justicia decir que eso sólo ocurre en un par de ocasiones ${ }^{1}$.

A pesar del influjo gongorino, que inspira el centro de interés de este artículo, la técnica con que l'orres Villarroel versifica la Conquista deja traslucir algo del prurito de claridad y orden, del didactismo más bien en este caso, que está en la atmósfera de la época. No olvidemos que una gran parte de la obra torresiana responde, de un modo $\mathfrak{u}$ otro, a ese didactismo. La estrofa tiene siempre un ritmo regular, con clara correspondencia de versos y elementos sintácticos. Después del cuarto verso el sentido y el ritmo suelen exigir una pausa, la cual divide la estrofa en dos mitades iguales ${ }^{2}$. En un diez por ciento de casos, aproximadamente ${ }^{3}$, sentido y ritmo exigen una pausa después de cada dos versos, lo que divide la estrofa en cuatro partes iguales. Falta, salvo cn un caso 4, y aun en éste no es del todo necesario, el enlace interestrófico.

Reproducimos a continuación el prólogo al lector, analizado en el párrafo 6 , y algunas estrofas de la Conquisla. El primero puede ser de interés para quienes se interesan por las ideas estético-literarias de la primera mitad del siglo xvirI ${ }^{5}$. Las segundas, seleccionadas con arreglo a un criterio antológico (pero sin olvidar la referencia a Góngora), son imprescindibles para que el lector pueda comprobar por sí mismo las afirmaciones contenidas en este artículo.

"Prólogo al leclor: Til héroe que ha elegido mi fatigado numen para objeto respectuoso ${ }^{\circ}$ de sus débiles números es un principe en quien concurren las dos

1 In la estrofa $\mathrm{I} 78$ (verso $\mathrm{I}$ ): "don Eustaquio Requibilli el animoson. $\mathrm{Y}$ en la estrofa 212 (verso 1 ): "cl conde Sifredi y el grande Garma".

2 lín sólo 16 estrofas, de las 231 del conjunto, no existe, con seguridad, esta pausa central.

3 Iin 22 estrofas, de las 23 r que tiene el poema.

- Iintre las estrofas 37 y 38 .

5 Sobre ćstis, después del trabajo fumdamental de Mráníndez Pera,ayo, en el tercer volumen de sul Mistoria de las illeas estélicas, no se ha investigado con la amplitul que del mucho tiempo transcurrido calbrla esperar.

- loorma culta etimológica por respel:toso. V. más adelante, dentro de este mismo prólogo, asumplos, succesivo y commercio. 
partes de entendimiento y brazo, ciencia y valor. Ia acción es de las más gloriosas y felices que han trabajado los épicos, pero el héroe y la acciún son tan morlernos que [no] ${ }^{1}$ deben sujetarse a las leyes del poema. I, o nuevo de la historia estrecha la invención y los episodios, que son toda la hermosura y ser de los poemas; y por esta razón quicren los épicos que sean señalados los arguncntos y asumptos antiguos.

Yo salvaria este inconveniente respondiendo con el Prfncipe de lisquilache, cu su Napoles restaurada [sic] a scmejatute reparo. Y' auncue no ne puclieran servir algunas de sus demonstrables soluciones ${ }^{2}$, a lo menos me bastaba la de procerler con la imitación de uu épico tan observante, tan culto y tan excelente en todo.

La observancin de las rigurosas leyes, tanto esenciales conı accidentales, del poema es la que siempre me quitó la phuma de la mano y la osadia de la imaginación para desear tal obra. In 'Tasso, Castelvetro y otros muchos, explicando la Podtica de Aristótcles, dan los cánones fieles para la expresión de los pocmas y ellos mismos las quebrantaron muchas veces en los suyos, siendo los varones uńs membrudos en esta casta de argumentos.

Yo he contentado el ansia cle escribir las glorias de nuestros españoles dictando en octavas solas esta Conquis/a. Por eso no pongo cantos y voy succesivo con la narración de la historia, huyendo de todo lo que pueda parecer poema.

Ios primeros y principales pasos de csta inimitable accirn sucerlicron cuanibo yo estaba en donde no of el commercio de las criaturas ni la voz de una gaceta. Después que, por la pieclad del rey, Mi Señor, esture entre mis anigos, juuté sus voces y tal cual relación de esta conquista, $y$ de estos son todos los matcriales con que se ha levantado este pobre y breve edificio.

Mi estilo siempre fue humilde $y$ aun abatido $y$, aumque pudiera con ei poder del ticmpo y las fuerzas de la imaginación darle alguna altura, no soy de sentir que scan útiles para la elevación de lo heroico las voces ásperas y ruiclosas, porque cllas son cspanto de necios y burla de ententidos. Con ellas se avinagra la dulzura y el numen y, mezcladas con la obscuridad, hacen intolerable la locución y desconocida la sentencia.

Iil tiempo que he gastado para escribir estas octavas ha sido corto, cl uso que yo lie tenido en lo heroico es ninguno, el ánimo no está en la acordada tranquilidad de su organización, el espiritu está ya fatigado y ni temperamento, con la edad, lia perdido parte de las fuerzas para el gusto y el trabajo.

Por todas estas razones merece algún clisimulo lo reducido y mal limarlo de la obra. Si me lo quieres conceder te estimıaré la piedad y, si 110, me consolaré con la fortuna de haber sido el primero que ha trabajarlo algo en poner en público una acción que servirá eternamente de houra y gloria para nuestra España. Vilıİ.»

1 I a palabra $n o$ falta en la clición de I 735 y ello trastorna el sentido del pasaje; corrijo con la de $175^{2}$.

2 Ijl Príncipe de Iisquilaclie se deficnde de la impugnación de obra histórica -de la que, según el, cra susceptible su poema- alegando razones no todas vilidas para 'lorres: mérito intrinseco del heroe (ésta si lo scria), dhecho de ser el descenticnte del mismo y el empeño esforzade de compensat con otros valores la reconocida deficiencia que entrañaba el contenido histórico. 
A fin de of recer a la atención del lector un texto de sentido coherente prescindimos de estrofas aisladas (incluso si son ilustrativas de lo que afirmamos) y reproducimos dos pequeños grupos de ellas. El primero (estrofas I3 a 25) empieza exaltando la grandeza del infante Carlos; presenta, luego, a éste despidiéndose de sus padres, y describe, por último, su travesía hasta Italia y el desembarco en este país. El segundo (estrofas 34 a 38) canta la salida de Parma y la llegada a Florencia, ciudad en la que Carlos es aclamado y que recorre en triunfo. Con la intención de facilitar las referencias asignamos a ambos pasajes una numeración marginal independiente, como si se tratase de textos completos.

\author{
El héroe canto, en el horror luciente: \\ el herce, aun en la gala fulminante, \\ que valeroso, arrebaludamente, \\ a rey ascender pudo desde infante. \\ 5 Infante soberano, tiernamente \\ la tinica vestido de diamante, \\ en quien solo, admirable, pudo Parma \\ ver armada la flor, florida el arma. \\ Carlos pueril, a quien el sol concede \\ Io que aun a la flor el fruto se anticipe: \\ Carlos inviclo, Adonis a quien cede \\ laurcles Febo, cristales Aganipe. \\ Cirlos, a quicn Amor hace que herede \\ trofeos de Isabel y de Felipe; \\ 15 Carlos, en fin, en quien copió blasones \\ la gloria de Farnesios y Borbones. \\ Carlos, que dulcemente se corona \\ hijo de uno feliz y otro consorle. \\ por Isabel progenie de Belona
}

6: la tinica vestido: el uso de verbos como vestir y calzar, con sentido activo y complenento que expresa la cosa vestida o calzada, es recurso gongorino. Cf. D. Alonso, La lengua poélica de Góngora, pp. 165-67.

8: armada la flor, florida el arma: la flor es la de la juventud del infante, la flor de su edad, unida ya, sin embargo, a la prestancia guerrera.

ıо: a la flor el fruto se anticipe: la flor, como queda diclıo, es la de su edad; el fruto, el de sus hechos gloriosos.

12: Aganipe: fucnte de las nusas, al pie del monte IIelicón, que también menciona (ióngorat (p. ej. "nl el verso 530 de la Suledad 2. $)$.

15: copió: en el sentido de 'acumuló, hizo acopio de'. 
$y$ por Felipe estirpe de Mavorte:

Carlos, cenlella de tuna y otra zona;

Carlos, lucero, palidez del norte;

todos en wno solo he de copiarlos. que de Quintos esencia es este Carlos.

25 Marte luciente, si Narciso horrendo: pelota el plomo, el bronce su juguete: dulce lo horrible, amable lo tremendo. gala el polvo, la polvora pebele; cancion la trompa, música el estruendo, delicia el parche y el fusil saincle, y la carla del ocio mds pintada toda le sale azar si no es la espada.

Suavidad de cordero al husón bebe y en sus armas león se ostenta luego: de I:Ina sagrado es un compendio breve, suplicio a la allivez y gracia al ruego: ni en al fuego derrite aqualla nieve ni la nieve apagar sabe aquel fucgo: quien la mano le besa juzga, ufano, que tiene a todo el cielo de sit mano.

Las fábulas hari su esfucrzo histurias de Alcides, de Jasones y Teseos; a Ramiros y a Alfonsos las victorias. a Iiclipes y Sinriques los trofeos.

45 a Luises y Fernandos las memorias imila y celo y fee a los Clodoveos:

24: de Quinlos esencia: alude al hecho de ser lielipe V padre del infante Carlos y, a la vez, al sentido de la palabra quintuesencia.

30: parche: el de los tambores que redoblan al iniciarse el ataque; sainele: aquí 'diversión, esparcinicnto'.

3r-32: aventuramos la siguiente interpretación de estos dos versos: la carta (naipe) mds pintada (pintar es 'mostrarse la pinta cle las cartas cuando se talla' según el Diccionario de la Real Academia, 19." el. s/r, acep. 9), del (por el) ocio toda le sale azar (no se cumple lo que la pinta anuncia) si no es la espada (en ésa sí se cumple en cuanto la espada anumcia sin lugar a dudas el destino guerrero del héroe).

33: al tusón: preferimos la lectura al tusón (ed. ae 1752); la ed. de I 735 tiene el tusón, que no da senticlo.

4I: nútese el hipérbaton: su esfuerzo hari (convertiri en) historias las fibulas..., es decir, lo consirlerarlo hasta aloora como legendinio pasará a tener la prosaica verosinilitud de la historia en comparacion con lats hazañas de Carlos; este desfile de personajes ejemplares recuerda la técnica elegiaca. 


\author{
a Alejandro Farnesio heredó el alma \\ y a Carlo Magno le robó la palma. \\ Diamantes españoles enternece, \\ 5o de caros padres cuellos dos enlaza \\ $y$ cn dos cuellos que cine le parece \\ que dos minndos, o cielos dos, abraza. \\ l'alcrno y' filial rostro se humedece. \\ llama el clarin y Amor se desengaza; \\ corona se le ha dado y, militante, \\ sale triunfando para ser triunfante. \\ Al teatro del orbe inds fecundo \\ por al tiunido mar ardiente vuela; \\ por agua empieza ya a juzgar el mundo \\ 6o y juzgavle tambien por fucgo anhela. \\ Su corazdn el buque es más profundo: \\ su aire el viento es, sul lizz la vela; \\ de sus sccrelos forma gabineles \\ y' en sus brlos tremola gallardeles. \\ 65 Su corazón magnanimo desprecia \\ los caballos marltimos de Ubalia; \\ el duodécimo Carlos de Stuecia. \\ el vencedor ardiente de Tesalia, \\ cl campedn bellgero de Grecia, \\ 7o bravo el carlaginés, horror de Italia, \\ forman en esle Carlos por blasones \\ in corazón de muchos corazones.
}

49: diamantes: alude a la firmeza de ánimo, conmovida, sin enbargo, de quienes despiden a Carlos.

54: se deschgaza: 'se desliga, se suelta'; es verbo formado sobre gaza; engazar es también palabra gongorina (verso 2 ro de la Soledad r.a, p. ej.).

57: teatro del orbe más fecundo: alude a Italia, a la que se dirige Carlos y donde van a tener lugar sus hiazañas.

59-60: el sentido es: empieza ya a juzgar el mundo por agua (en su impaciencia) y' anhela juzgarle también por fuego (entrando en combate).

6r-64: versos de senticlo confuso; proponemos esta interpretación: su corazón (el de Carlos) es el buque más profundo (el que más profundamente surca el mar, o sea, que es el esforzado corazón de Carlos el que presta impulso a la travesia); su aire (impetu) es el ricnto (que empuja las velas), su luz (clarividencia) la vela (que mantiene el rumbo debiclo); de sils secretos (de los misteriosos designios del mar) forma gabineles (es decir, penetra en sus arcanos y los doblega a servirlo) y cu sus brios (los del mar) tromola gallardetes (los de su victoria sobre el elemento If(quiclo).

Gi: caballos marllimos: 'natres'; Ubalia: Inglaterra.

6S-7o: alusiones a César, Alejandro y Anibal. 
Celcbra mar y cielo tanta muestra y lanlo alarde, de Belona ensayo:

75 en mar y lierra ofrecen a su diestra el tridente Neptisno y Jove el rajo: admira viento y agua en su palestra, si volunte al abril, radiante al mayo: las sirenas le clan feliz pasaje

$80 \quad y$ toda su canción es buen viaje.

Roca es cada brjel endurecida que respecta la onda escarmentada, y aferrante tenaz, cuanto atrevida, la rémora de si lo es admirada:

85 los delfines celebran sis partida con carrera espumante torneada: consanguineo es a Carlos el respelo, pues de "n Delfin le reconocen nielo.

De zafiro en celestes arreboles

90 lodo en gracias el mar vuclue sus salcs: misica es el bramar de caracoles. sus escollos son troncos de corales; rayos al norte suple por mil soles $y$ centellas resurten los crislales:

95 mi es menester abrirlas para verlas, que de las conchas brótanse las perlas.

Ya a los campos conclama de Satumo: tierra toma y felice llega a Parma, j. Aquiles español, hesperio Turno,

78: abril ... mayo: los meses primaverales son también expresivos de la juventud del infante.

79: pasaje: aquí con el sentirlo de 'paso libre', en contra de la normal condición de las sirenas, que, con su canto, hacian doruirse y, en consecuencia, naufragar a los navegantes.

82: onda escarmentada: por liaberla antes doblegado la proa de los navios. 83-84: la rémora, aferrante (tan) tenaz cuanto (como) atrevida, lo es (aferrante) adinirada de sí (de su propio valor al aferrarse a las naves de Carlos).

86: Iormeada: de giros y cabriolas, que sugiere redondeces de volutas.

88: efectivanente, Carlos era nieto del Gran Delfín de Irancia, hijo de Iuis XIV.

90: gracias ... sales: se jucga con el senticlo; las gracias son las 'gratitudes' y los 'elonaires'; las sales son lats del mat y tambien los domaires.

97: los campos ... de Salurno: Italia, de la que Saturno fue monarca mitico; conclana: 'convoca'.

99: Turno: era rey de Rutilia en el ticmpo de la llegarla de Eneas a Italia. 
100 palria materna de esplendores arma. Parma le admira luminar diurno, pues de sangre y naufragio la desarma con dos arcos el hijo de Tomiris: uno el arco de Amor, el otro el Iris.

I05 De Parma Carlos sale, a quien corona prepara la divina providencia: entra en Florencia, pero en su persona entra o lleva consigo otra Florencia. Una amante, otra amada se eslabona, Iro que si ha sido por sil correspondencia pequeño mundo el hombre, en su modelo se oslcula Carlos, abreviado cielo.

Rimclenle los afeclos por despojos y aun los silencios son admiraciones;

I 5 y'a a los labios le pasan de los ojos $y$ de los labios a los corazones: ternezas a su amor son los arrojos, confesando que en sus aclamaciones son de la fama, en drticos confines, mudas las lenguas, roncos los clarines.

Serenlsimo el claro bello infanle no tan solo es de pechos varoniles glorioso triunfador, pero brillanle roba dulce atenciones femeniles:

100: patria materna: Isabel de Farnesio, madre del infante Carlos, era italiana. ro2-rof: el hijo de Tomiris (Carlos, a cuya madre se compara con Tomiris, reina de los masajetes, vencedora de Ciro) la desarma (a la ciudad) de sangre (violencia cruenta) y nanfragio (nal gobierno) con dos arcos (paradójicamente, por ser el arco instrumento guerrero): uino el arco de Amor (opuesto naturalmente a la violencia y al odio), el otro el Iris (o sea, el arco iris, opueste a la tormenta o al naufragio, cuyo final señala).

109-I 12: tha (I'lorencia) antante (Carlos que, como queda dicho, vale por su persona una Florencia), otra (1'lorencia) amada (la ciudad) se eslabona(n) (se unen cn reciproco anor), que si (pues si) el hombre (singular genérico, equivale a los hombres) ha sido (lasta alıora) pequeño mundo por su correspondencia (si ningún gobernante ha estado a la iltura de merecer el amor de la ciudad), Carlos, cielo abrcindu (compentio de virtules celestiales) su ostenta en (como) sil modelo (arquetipo de valores que cautiva a lat ciudad).

123: pero: sentido de 'sinss'. 
125 admiran en su angelico semblanle. muchas las flores, pocos los abrilcs, en su vulto anhelando delicioso conseguirle galán, ya que no esposo.

Por sólo este botón que Itesperia alcanza

I30 de sil ajada estacion fcliz florece, $y$ ', marchita en dos siglos la esperanza. por aquesta flor sólo reverdece: ya a la tormenta sigue la bonanza: pimpollo nace, pero cedro crece, I35 que inundard, del tronco de la Galia, de dimbar a Hesperia, si de aroma a Italia.

Por luceros describe su ascondencia eni el etéreo cristalino claustro, y hoy en oposicion su descendencia

r fo del Austro vicne y vuclue contra el Austro; el sol a su divina refulgencia de tres insignias le construye claustro, estampando en su escullo por blasones las dguilas, las lises y leones.

Confiamos en que las notas aclaratorias de las estrofas que reproducimos hayan servido al lector para confirmar la presencia de los desmaños y confusiones a que aludíamos antes. Precisamente en esta voluntad de sintaxis difícil reside, a nuestro jucio, uno de los rasgos claramente gongorinos de la Conquista.

\section{Luis López Molina}

I27: villo: 'rostro'; es palabra reiterada por Góngora (p. ej. en Soledad r.a, verso 777 , y en Soledad 2. 2 , verso 463 ).

I29: botón: 'brote o yema'; nueva alusión a la jurentud del infante.

135: del tronco de la Galia: se refiere a la estirpe francesa cle Carlos.

136: la fórmula $A$ si $B$ ell este verso, como en otros de Góngora y del misuo Torres, está vaciada de sentido adversativo.

137-40: describe (Carlos) su ascendencia por luceros (o sea, sus ascendientes son otros tantos luceros) en el etéreo cristalino claustro (el ciclo) y hny en oposición (por el contrario, en contraposición; se preficre oposición por ser palabra de astronomia) su descendencia (la de csos luceros, o sca, Carlos mismo) del Ausiro (del Sur, de lispaña) vicne $y$ vuclve contra cl anstro (contra Italia, pais así mismo nucriclional). la referencia al $\Lambda$ ustro se encuentra también en Góngora (p. ej. cn Soledad r. a, versos 703 y 1033). 